NO. Can Fam Physician 2010;56(2):127, 129, 131, 133; discussion e50, e52

19. Luks VP, Vandemheen KL, Aaron SD. Confirmation of asthma in an era of over diagnosis. Eur Respir J 2010;36:255-60. http://dx.doi.org/10.1183/ 09031936.00165109

20. Lusuardi M, De Benedetto F, Paggiaro P, et al. A randomized controlled trial on office spirometry in asthma and COPD in standard general practice: data from spirometry in asthma and COPD: a comparative evaluation Italian study. Chest 2006;129(4):844-52. http://dx.doi.org/10.1378/chest.129.4.844

21. D'Urzo AD. Does family medicine have a professional obligation to play a leading role in pharmaceutical industry-sponsored drug research?: yes. Can Fam Physician 2011;57(8):870, 872, 874, 876; discussion e277, e279.

22. van Schayck CPO, Levy ML, Stephenson P, Sheikh A. The International Primary Care Respiratory Group (IPCRG) Guidelines for the Management of Chronic Respiratory Diseases in Primary Care. Prim Care Respir J 2006;15(1):1-4.

23. Price D, Musgrave SD, Shepstone L, et al. Leukotriene Antagonists as First-Line or Add-on Asthma-Controller Therapy. N Engl J Med 2011;364:1695-707. http://dx.doi.org/10.1056/NEJMoa1010846

\title{
The role of primary care as part of the multidisciplinary team (MDT) in the management of lung cancer: the "Dream MDT" report - new guidance from the UK Lung Cancer Coalition
}

\section{*David Bellamy', Mick Peake², Andrea Williams ${ }^{3}$}

1 Retired general practitioner; member of the UK Lung Cancer Coalition

2 Consultant and Senior Lecturer in Respiratory Medicine, University Hospitals of Leicester, Leicester, UK; Clinical Lead for the UK National Cancer Intelligence Network (NCIN) and the UK National Lung Cancer Audit Programme (NLCA); Chairman, clinical section of the UK Lung Cancer Coalition

3 General practitioner, King Street Surgery, Hereford, UK; GP adviser for Herefordshire Clinical Commissioning Group; GP spokesperson for the UK Lung Cancer Coalition

*Correspondence: Dr David Bellamy, 8 Littledown Drive, Bournemouth, BH7 7AQ

Tel: +44 (0)1202 394443 E-mail: david.bellamy@virgin.net

Lung cancer is one of the commonest cancers in the UK, with 39,000 new cases diagnosed each year -1 in 7 of all cancers. It causes 35,000 deaths annually, ${ }^{1}$ more than breast and prostate cancer combined. Globally, large increases will occur in developing countries such as China due to increased smoking prevalence. Traditionally men have been more frequently affected than women; however, in the last five years a decline in incidence in males has been observed, whereas incidence rates in women are increasing so that lung cancer has now overtaken breast cancer as a cause of death in women.

Overall, lung cancer has a very poor prognosis which sadly has improved relatively little in the last 40 years. Only $21 \%$ of patients are alive after one year and at five years a mere $9 \%$ are still surviving. ${ }^{2}$ Survival in the UK is three percentage points lower than the European average and seven to 10 points lower than the USA. It has been estimated that 3,500 lives could be saved each year if UK survival rates were improved to be the best in Europe. ${ }^{3}$ Recent research has shown that $39 \%$ of lung cancer patients first present as an emergency admission to hospital and that these patients have a significantly worse prognosis. ${ }^{4}$

There is also evidence of wide variation in the management and outcomes of patients with lung cancer within the UK itself. ${ }^{5}$ The UK
National Lung Cancer Audit has shown that the proportion of patients undergoing surgical treatment varies by a factor of about four between various hospital multi-disciplinary teams (MDTs) throughout the UK, and that most of this variation is not explained by case mix variables.

Studies looking for explanations as to why UK survival figures for lung cancer are so poor have identified a number of contributory causes. One of the main problems is that the vast majority of patients do not present to specialist care until their disease has advanced to a stage when it is essentially incurable. One study comparing excess deaths between England, Norway and Sweden, demonstrated that England had a higher proportion of excess deaths at five years in all age groups but that the large percentage of these excess deaths could be explained by deaths within three months of diagnosis. ${ }^{6}$ Since there are no screening programmes in any of the three countries, the implication has to be that patients with symptomatic lung cancer are getting treatment earlier in Scandinavia. The public are poorly informed about lung cancer symptoms ${ }^{7}$ and seem to have little idea of the scale of risk of lung cancer from smoking. In a recent Scottish study, the median time from the earliest reported symptom to consultation was 99 days $^{8}$ and a questionnaire revealed that $75 \%$ of participants had unrecognised symptoms of lung cancer. The presence of COPD, which increases the risk of lung cancer up to five times, ${ }^{9}$ often delays diagnosis. Estimates suggest that the causes for delay between first symptom and presentation to specialist care can be split equally between patient-related and primary care-related issues. ${ }^{10}$

In order to increase public awareness about lung cancer, the UK Department of Health funded a pilot, high profile media campaign in the Midlands region of England for a 5-week period in October and November 2011. This used the brand 'Be Clear on Cancer', and encouraged people over 50 with a persistent cough, the commonest symptom of lung cancer, to seek advice from their general practitioner (GP). A national campaign followed in the summer of 2012 and the results of these initiatives are awaited with interest.

In a further attempt to address these problems, a team of lung cancer experts from primary and secondary care, representing the UK Lung Cancer Coalition, has just published a new report in order to define the "Dream Multidisciplinary Team for lung cancer". ${ }^{11}$ This 
"Dream MDT" report highlights how primary care physicians can play a vital role in the early diagnosis, referral and continuing care of lung cancer patients. The report is intended to act as an aspirational standard and as a focus for discussion, thereby helping deliver high quality lung cancer care for all patients and (hopefully) improving survival rates. Its aim is to describe the standard of care that we would all want for ourselves or our families.

Recommendations from the "Dream MDT" report that relate specifically to primary care include:

- GPs could be better linked-in to the MDT, given that they are an important point of contact and information for patients and carers

- GPs should receive sufficient information from the hospital to determine what has and has not been discussed with the patient and carers, particularly treatments and prognosis. They will then be more able to have meaningful discussions with patients and carers

- More time in consultations and copying patients into correspondence would also be a worthwhile change to practice

- Reports of all chest x-rays and CT scans - where the possibility of a diagnosis of lung cancer is raised - should be sent urgently both to the referring clinician and to the lung cancer team, or should automatically trigger a referral

- Where the chest $x$-ray is suspicious of a lung tumour, a contrastenhanced CT scan of the chest, neck and upper abdomen should be carried out and be available at the first clinic visit

- The interval between GP referral to first attendance in the specialist clinic should be as short as possible - ideally no more than a week

- Patients should be told why they are being referred and be given access to a clinical nurse specialist from the time of referral. ${ }^{11}$

Although a common cancer, most GPs will see only one to two new cases of lung cancer a year. The symptoms are similar to many other more common diseases. Making a diagnosis is often not easy. When symptoms such as haemoptysis occur there is often rapid referral, but more non-specific symptoms of fatigue and weight loss may not always alert to the possibility of lung cancer. The NICE 2011 lung cancer guideline update strongly supports the need for a prompt chest $x$-ray with any symptoms suggesting lung cancer which have persisted for more than three weeks. ${ }^{12}$ A chest $x$-ray will show abnormalities in over $90 \%$ of patients with lung cancer but it is important to remember that a normal $x$-ray does not exclude a diagnosis of lung cancer and that if there is a high index of clinical suspicion the patient should be referred quickly to the local chest physician. It is also good practice to perform a chest x-ray on newly diagnosed COPD patients, since there is much overlap in smoking pathogenesis and symptoms. The recently published UK NICE Quality Standards stress the importance of rapid referral for people reporting one or more symptoms of lung cancer and emphasise the importance of a multidisciplinary team approach to optimal care. ${ }^{13}$

The "Dream MDT" report also discusses GPs' access to other diagnostic tools such as computed tomography (CT) scanning and suggests that this should be made easier. This may be an area that local UK Clinical Commissioning Groups (CCGs) might negotiate if felt desirable. Another important aspect of good general practice is the 'significant' or 'serious event' review process, whereby primary care teams hold regular case discussions on newly diagnosed cancers, particularly if the symptoms were unusual or where the patient had first presented to hospital as an emergency.

It is clear that GPs and the wider primary care team have a vital role to play in the earlier diagnosis of lung cancer and in the support of patients and their families after diagnosis. Ultimately, there needs to be better communication and interface between primary and secondary care. Lung cancer patients deserve it, and GPs should demand it.

Acknowledgements The UK Lung Cancer Coalition (UKLCC) is the UK's largest multi-interest group in lung cancer. It is a powerful partnership of the leading lung cancer charities, clinicians, healthcare professionals and healthcare companies which are committed to, and have a shared interest in, improving lung cancer survival and the quality of life for people with lung cancer.

Conflicts of interest DB is an Associate Editor of the PCRJ, but was not involved in the editorial review of, nor the decision to publish, this article. The authors declare that they have no conflicts of interest in relation to this article.

Commissioned article; not externally peer-reviewed; accepted 27th November 2012; online 29th January 2013

( 2013 Primary Care Respiratory Society UK. All rights reserved

http://dx.doi.org/10.4104/pcrj.2013.00007

Prim Care Respir J 2013; 22(1): 3-4

\section{References}

1. Data from Cancer Research UK, accessed October 2012 and available at: http://info.cancerresearchuk.org/cancerstats/types/lung/mortality/

2. Data from Cancer Research UK, accessed October 2012 and available at: http://info.cancerresearchuk.org/cancerstats/mortality/cancerdeaths/?a=54413

3. Coleman MP, Foreman D, Bryant $\mathrm{H}$, et al. Cancer survival in Australia, Canada, Denmark, Norway, Sweden and the UK (the International Benchmarking Partnership): an analysis of population based cancer registry data. Lancet 2011; 377:127-38. http://dx.doi.org/10.1016/S0140-6736(10)62231-3

4. Elliss-Brookes L, McPhail S, Ives A, et al. Routes to diagnosis for cancer determining the patient journey using multiple routine data sets. $\mathrm{Br} J$ Cancer 2012;107(8):1220-6. http://dx.doi.org/10.1038/bjc.2012.408

5. NHS Information Centre. National Lung Cancer Audit, Annual Report 2011 Available via: www.ic.nhs.uk

6. Holmberg L, Sandin F, Bray F, et al. National comparisons of lung cancer survival in England, Norway and Sweden 2001-2004: differences occur early in follow-up. Thorax 2010;65:436-41. http://dx.doi.org/10.1136/thx.2009.124222

7. Simon A, Juszcyk D, Smyth $N$, et al. Knowledge of lung cancer symptoms and risk factors in Britain - development of a measure and results from a population-based survey. Thorax 2012;67:426-32. http://dx.doi.org/10.1136/thoraxjnl-2011-200898

8. Smith SM, Campbell NC, MacLeod U, et al. Factors contributing to the time taken to consult with symptoms of lung cancer. Thorax 2009;64:523-31. http://dx.doi.org/10.1136/thx.2008.096560

9. Barnes PJ, Celli BR. Systemic manifestations and co-morbidities of COPD. Eur Respir J 2009;33:1165- 85. http://dx.doi.org/10.1183/09031936.00128008

10. Jensen AR, Mainz J, Overgaard J. Impact of delay on diagnosis and treatment of primary lung cancer. Acta Oncol 2002;41:147-52. http://dx.doi.org/10.1080/ 028418602753669517

11. The Dream MDT for lung cancer. UK Lung Cancer Coalition November 2012 Available at: www.uklcc.org.uk

12. National Institute for Health and Clinical Excellence. The diagnosis and treatment of lung cancer (update). Clinical Guideline 121, London; NICE, 2011. Available at; www.nice.org.uk/CG121

13. National Institute for Health and Clinical Excellence website. Lung cancer for adults quality standard. Available at: www.nice.org.uk/guidance/qualitystandards/ lungcancer/home.jsp 